\title{
Daily blood pressure profile in Cushing's syndrome before and after surgery
}

A. Kreze $\mathrm{K}^{1}$ and

M. Mikulecky²

\author{
${ }^{1}$ Institute of Clinical Endocrinology, Lubochna, Slovak Republic \\ ${ }^{2}$ Institute of Preventive and Clinical Medicine, Bratislava, Slovak Republic
}

\section{Correspondence \\ A. Kreze \\ Institute of Endocrinology \\ SK 03491 Lubochna \\ Slovak Republic \\ Fax: + 42-1-8489-1273 \\ E-mail: mikuleky@upkm.sk \\ Research supported by the Ministry of Health of the Slovak Republic \\ (No. 04.92.36).}

Received January 6, 1998 Accepted August 4, 1999

\section{Abstract}

No significant difference has been demonstrated in the altered circadian blood pressure pattern between the pituitary-dependent and adrenal forms of Cushing's syndrome before surgery. The effect of therapy, however, proved to be different. The mesor was normalized in the pituitary-dependent Cushing's syndrome more conspicuously for systolic than for diastolic blood pressure. In Cushing's syndrome due to adrenal adenoma, systolic and diastolic blood pressure mesors have been even significantly "overnormalized" after treatment, being 11 to 27 and 2 to $13 \mathrm{mmHg}$ ( $95 \%$ confidence) lower than corresponding mesors in controls. There was no difference between forms in the effect of treatment on blood pressure amplitudes, which remained significantly lower than in controls. Finally, acrophase patterns were partly normalized after treatment of the pituitary-dependent form only for diastolic blood pressure, while both systolic and diastolic blood pressure acrophases were normalized in the treated adrenal form. In conclusion, complete normalization of the pattern of daily blood pressure profile has not been achieved in either form of the syndrome. This may be one of the reasons for the reduced long-term survival after surgical cure of hypercortisolism, than expected.

\section{Introduction}

The daily blood pressure (BP) rhythm in Cushing's syndrome matches that of cortisolemia, which typically differs $(1,2)$ from the normal pattern $(3,4)$. The same is true for $\mathrm{BP}$ : in contrast to its normal daily profile (5), there is an increase of both systolic and diastolic BP values, a decrease of their day/ night variation and a time shift of their highest values towards night or morning hours $(6,7)$. The aim of the present study was to verify these features and to determine whether they are normalized after successful surgical

\section{Key words}

- Cushing's syndrome

- Pituitary-dependent Cushing's syndrome - Cushing's syndrome due to adrenal adenoma

- Blood pressure

- Circadian rhythm

- Surgery therapy in the two different pathogenetic forms of Cushing's syndrome. This issue has been addressed, so far, without considering the chronobiology of BP (8) and sometimes also without differentiating the pathogenetic forms of Cushing's syndrome $(9,10)$.

\section{Patients and Methods}

Twenty-one patients with Cushing's syndrome were studied (Table 1). The diagnosis was confirmed in 19 by histological examination of surgical specimens. In 2 patients who refused the recommended surgery, the 
diagnosis of pituitary-dependent Cushing's syndrome was based on clinical findings, laboratory tests, and abdominal and sella turcica computed tomography scans. The circadian cortisolemia pattern after surgery in patients submitted to replacement therapy was normal in all cases. BP was monitored 2-3 weeks before and/or 2-12 months after surgery.

Fifteen volunteer normotonic, nonobese (body mass index 19-24) healthy members of the nursing and laboratory staff ( 3 males and 12 females aged 21-58 years) served as controls for blood pressure monitoring. Informed consent was obtained from each subject.

BP was monitored automatically every $15 \mathrm{~min}$ for $48 \mathrm{~h}$ by the noninvasive cuffoscillometric method using the Tensostar instrument (Chirana, Stara Tura, Slovak Re-

Table 1 - Data for 21 patients with Cushing's syndrome ( $P D=$ pituitary dependent, $A A$ = adrenal adenoma) with $27 \mathrm{BP}$ monitoring runs before and/or after surgery (TSA = transsphenoidal adenotomy, BLA = bilateral adrenalectomy, ULA = unilateral adrenalectomy).

$M=M$ ale,$F=$ female $A=$ antihypertensive drug,$R=$ replacement therapy, $M=$ blood pressure monitoring performed.

\begin{tabular}{lccccc}
\hline $\begin{array}{l}\text { Patient } \\
\text { No. }\end{array}$ & Form $\begin{array}{c}\text { Duration } \\
\text { (year) }\end{array}$ & Sex & $\begin{array}{c}\text { Age } \\
\text { (year) }\end{array}$ & Surgery & Therapy and monitoring \\
\cline { 4 - 5 } & & & Before surgery After surgery
\end{tabular}

\begin{tabular}{|c|c|c|c|c|c|c|c|}
\hline 01 & PD & 0.5 & $\mathrm{~F}$ & 16 & TSA & A M & R M \\
\hline 02 & PD & 1 & $\mathrm{~F}$ & 45 & TSA & $M$ & $M$ \\
\hline 03 & PD & 5 & $\mathrm{~F}$ & 43 & BLA & A M & ARM \\
\hline 04 & PD & 3 & $\mathrm{~F}$ & 25 & BLA & $M$ & R M \\
\hline 05 & PD & 3 & $\mathrm{~F}$ & 45 & TSA & $M$ & $R$ \\
\hline 06 & PD & 1 & $\mathrm{~F}$ & 56 & TSA & $A M$ & $A R$ \\
\hline 07 & PD & 0.2 & $F$ & 37 & TSA & $A M$ & $\mathrm{R}$ \\
\hline 08 & PD & 3 & $F$ & 38 & & A M & \\
\hline 09 & PD & 5 & $\mathrm{~F}$ & 36 & & $A M$ & \\
\hline 10 & PD & 2 & $\mathrm{~F}$ & 49 & TSA & & R M \\
\hline 11 & PD & 2 & $\mathrm{~F}$ & 38 & TSA & & R M \\
\hline 12 & PD & 3 & $\mathrm{~F}$ & 57 & BLA & $A$ & R M \\
\hline 13 & PD & 2.5 & $M$ & 20 & BLA & & R M \\
\hline 14 & AA & 2 & $\mathrm{~F}$ & 22 & ULA & $M$ & R M \\
\hline 15 & AA & 1 & $\mathrm{~F}$ & 29 & ULA & A M & R M \\
\hline 16 & AA & 3 & $M$ & 27 & ULA & $A M$ & $\mathrm{R}$ \\
\hline 17 & AA & 0.5 & $\mathrm{~F}$ & 34 & ULA & $\mathrm{A} M$ & \\
\hline 18 & AA & 1 & $\mathrm{~F}$ & 29 & ULA & A & $M$ \\
\hline 19 & AA & 1 & $\mathrm{~F}$ & 29 & ULA & & $M$ \\
\hline 20 & AA & 3 & $\mathrm{~F}$ & 40 & ULA & $A$ & R M \\
\hline 21 & AA & 1.5 & $\mathrm{~F}$ & 44 & ULA & & M \\
\hline
\end{tabular}

public). At the start of each run, the automatic measurements were validated with a mercury sphygmomanometer. All 27 monitoring runs were performed in a ward setting, with the subject in a recumbent position. Probands were allowed to leave the bed for bathroom needs between measurements. Breakfast was served at 7:30, lunch at 12:00, and the evening meal at 18:00. All lights were turned off at 21:30, and probands were awakened at 6:30.

The data obtained [available upon request at $<$ mikuleky@upkm.sk>] were analyzed by the cosinor regression method (11) using an original computer program (12). The resulting estimates of mesor (analogy to the daily mean value throughout the $24 \mathrm{~h}$ ), amplitude (the range between estimated daily maximal value and mesor) and acrophase (the estimated time of the daily maximal value) were expressed as nonparametric $95 \%$ confidence intervals for each group (13). The difference between untreated Cushing and control values of BP parameters was evaluated by the Mann-Whitney test, with the level of significance set at 0.05 . The $95 \%$ confidence intervals were computed for the difference between treated patients and controls (14).

\section{Results}

The results are shown in Table 2 and Figure 1A,B. The increase of systolic and diastolic BP mesor (with wider ranges in the adrenal form of the syndrome), the decrease of their amplitudes and the alteration of acrophases were similar in both untreated pituitary-dependent and adrenal Cushing's syndrome. After the surgical removal of hypercortisolism, a decrease of systolic and, to a lesser extent, of diastolic mesor was observed in both forms of the syndrome. In the adrenal form this decrease even tended to reach hypotensive values. The decreased amplitude of both systolic and diastolic BP persisted after surgery. The normalization of 
the timing of BP peaks was achieved by the surgical removal of hypercortisolism for diastolic BP in the pituitary-dependent form and for systolic and diastolic BP in the adrenal form of Cushing's syndrome.

\section{Discussion}

Our results confirm previous reports by others on this issue $(6,7)$. In untreated Cushing's syndrome there is indeed a general increase of blood pressure values, a diminished day/night variation and a time shift of the highest blood pressure values. The present study extended these findings by the systematic and rigorous analysis of blood pressure circadian rhythm after surgical removal of hypercortisolism.

Evaluations of the effect of surgical removal of hypercortisolism on blood pressure have been based previously on casual blood pressure measurements only, without considering circadian fluctuation $(8-10,15)$. Moreover, these reports do not mention differences between the pituitary-dependent and adrenal form of the syndrome after surgery. The data for decreases of systolic and diastolic blood pressure after surgery are in good general mutual agreement, reporting a fall of approximately $40 \mathrm{mmHg}$ in systolic blood pressure and a fall of $24 \mathrm{mmHg}$ in diastolic blood pressure. They also roughly agree with our data, except for the marked differences between the two pathogenetic forms of the syndrome revealed by the present study. Our results confirmed those of others, showing that systolic blood pressure was normalized to a greater extent than diastolic blood pressure (15). However, the opposite result was reported for children and adolescents (10). The report in the literature that there were no differences between the two most frequent pathogenetic forms of Cushing's syndrome (8) is also at marked variance with our findings.

The present paper does not deal with a time course of the therapeutic effect on blood pressure during months and years after surgery. Studies focusing on this point (8-10) showed rapid improvement a few months after surgery, with some $(8,10)$ or no (9) improvement later. The duration of hypertension in Cushing's syndrome appears to be the determinant of persistent hypertension following successful surgery (16). Indeed, one of our few patients who required antihypertensive treatment after surgery had the longest duration of Cushing's syndrome with hypertension of all the patients in the study.

Clinically, the most important product of our chronobiological study appears to be the fact that the circadian pattern of blood pressure was not fully normalized in either pathogenetic form of Cushing's syndrome. A decreased amplitude without substantial change persisted in both forms; moreover, the derangement of the acrophase for systolic blood

Table 2 - Lower-upper limits of the 95\% confidence intervals (for the adrenal form of the syndrome before surgery, only the ranges are given) for chronobiological parameters of blood pressure in control and Cushing samples.

Significant differences between groups were determined by the Mann-Whitney test (a-a to e-e) and by the confidence intervals for the difference (A-A to G-G, Figure $1 A, B$ ). Values followed by the same letter differed significantly.

\begin{tabular}{|c|c|c|c|c|}
\hline Sample & $\begin{array}{l}\text { Sample } \\
\text { size }\end{array}$ & $\begin{array}{l}\text { Mesor } \\
(\mathrm{mmHg})\end{array}$ & $\begin{array}{l}\text { Amplitude } \\
\text { (mmHg) }\end{array}$ & $\begin{array}{l}\text { Acrophase } \\
\text { (clock hours) }\end{array}$ \\
\hline Controls & 15 & & & \\
\hline Systolic & & $105-123^{2} \mathrm{~A}$ & $4-11^{c} C D$ & 3 p.m. -6 p.m. ${ }^{e} \mathrm{G}$ \\
\hline Diastolic & & $69-81^{b} B$ & 5-9deF & 3 p.m.-6 p.m. \\
\hline \multicolumn{5}{|l|}{$\begin{array}{l}\text { Pituitary } \\
\text { before surgery }\end{array}$} \\
\hline Systolic & & $115-136^{a}$ & $3-6^{c}$ & 9 p.m. -5 a.m. ${ }^{e}$ \\
\hline Diastolic & & $79-97^{b}$ & $1-5^{d}$ & 8 a.m.-1 a.m. \\
\hline \multicolumn{5}{|l|}{ Pituitary } \\
\hline Systolic & & $106-126$ & $3-8 C$ & 5 p.m.-5 a.m.G \\
\hline Diastolic & & $77-86$ & $2-6 E$ & 2 p.m.-1 a.m. \\
\hline \multicolumn{5}{|l|}{ Adrenal } \\
\hline before surgery & 4 & & & \\
\hline $\begin{array}{l}\text { Systolic } \\
\text { Diastolic }\end{array}$ & & $\begin{array}{l}(98-165) \\
(69-105)\end{array}$ & $\begin{array}{l}(2-7) \\
(3-7)\end{array}$ & $\begin{array}{l}\text { (4 p.m.-4 a.m.) } \\
\text { (5 a.m.-12 a.m.) }\end{array}$ \\
\hline \multicolumn{5}{|l|}{ Adrenal } \\
\hline Systolic & & $88-101 A$ & $2-11 D$ & 3 p.m.-7 p.m. \\
\hline Diastolic & & 63-71B & $1-7 \mathrm{~F}$ & 1 p.m.-6 p.m. \\
\hline
\end{tabular}


Figure 1 - A, Left: Response of blood pressure (BP, $\mathrm{s}=$ systolic and $\mathrm{d}=$ diastolic) mesor ( $\mathrm{M}$ ) and amplitude (A) to therapy. The difference (PT-C, vertical axis) between treated pituitary-dependent Cushing's syndrome (PT) and controls (C, represented by zero value on the vertical axis) is shown as median difference (horizontal heavy lines) and 95\% confidence intervals (shadowed bars). Right: Analogy for acrophase displayed on clock hours scale. The intervals for BPs and BPd after treatment are shown versus controls' acrophase time N (4 p.m.). B, Analogy for the difference (AT-C) between treated Cushing's syndrome due to adrenal adenoma (AT) and controls (C)

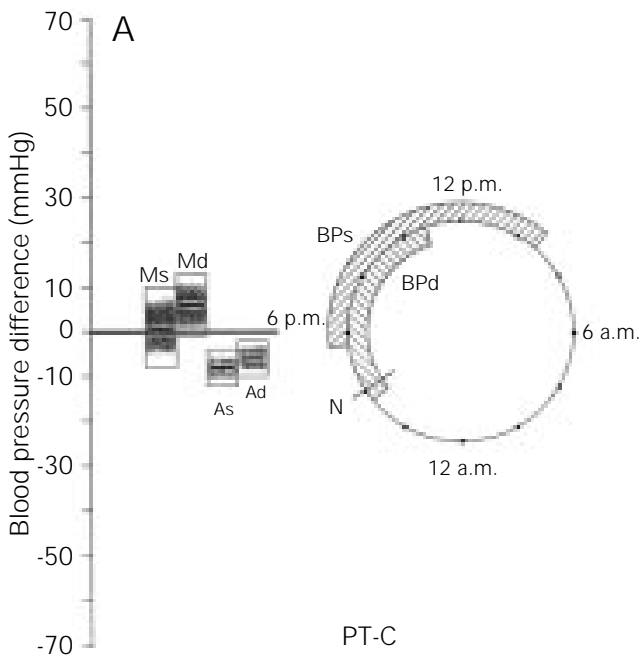

pressure persisted in the pituitary-dependent cases. The amplitude and acrophase changes cannot be assessed by "office" blood pressure measurements. In the adrenal cases the mesors of systolic and diastolic blood pressure were excessively reduced towards hypotensive values.

Despite the improved clinical blood pressure status of almost all patients, the described chronobiological aberrations, not

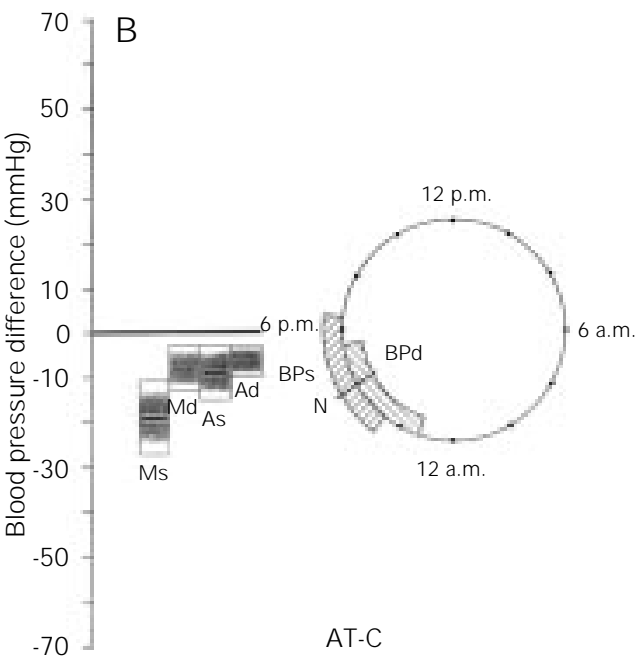

demonstrable by the common static blood pressure measurements, contribute to the observations $(17,18)$ that the removal of hypercortisolism per se does not result in improved survival.

\section{Acknowledgments}

The authors thank Dr. Marian Moravcik for technical assistance.

\section{References}

1. Krieger DT (1982). Cushing's Syndrome. Springer-Verlag, Berlin, Heidelberg, New York.

2. Kreze A, Spirová E, Sánchez de la Pena S, Cugini $P$, Mikulecky $M$, Halberg $E \&$ Halberg $F$ (1987). Altered circadian plasma cortisol and aldosterone group rhythm in Cushing's syndrome versus obesity and health. In: Pauly JE \& Scheving LE (Editors), Advances in Chronobiology. Alan Liss Inc., New York, 203-217.

3. Weitzmann ED, Fukushima DK, Nogeire Ch, Roffwarg H, Gallagher TF \& Hellman $L$ (1971). Twenty-four hour pattern of the episodic secretion of cortisol in normal subjects. J ournal of Clinical Endocrinology and Metabolism, 33: 14-22.

4. Mikulecky M, Kreze A, Putz Z \& M oravcik $M$ (1995). Daily variation of serum cortisol, 17-hydroxyprogesterone and five androgens in healthy women. Brazilian J our- nal of Medical and Biological Research, 28: 485-490.

5. Millar-Craig MW, Bishop CN \& Raftery EB (1978). Circadian variation of blood pressure. Lancet, 1: 795-797.

6. Imai $Y$, Abe K, Sasaki S, Minami N, Nihei M, Munakata M, Mukurami O, Matsue $K$, Sekino H, Miura Y \& Yoshinaga K (1988). Altered circadian blood pressure rhythm in patients with Cushing's syndrome. Hypertension, 12: 11-19.

7. Piovesan A, Panarelli M, Terzolo M, Osella G, Matrella C, Pacotti P \& Angeli A (1990). 24-hour profiles of blood pressure and heart rate in Cushing's syndrome: relationship between cortisol and cardiovascular rhythmicities. Chronobiology International, 7: 263-265.

8. Knappe G, Gerl H \& Ventz M (1991). Blood pressure before and after surgical treatment of 66 patients with Cushing's syn- drome. Acta Endocrinologica, 124 (Suppl 1): 60 (Abstract).

9. Shustov SB, Yakovlev VA, Krasnov LM \& Baranov VL (1996). Pre- and postsurgical treatment condition of cardiovascular and endocrine systems in patients with endogenic hypercortisolism (in Russian). Klinicheskaia Meditsina, 74: 33-36.

10. Magiakou MA, Mastorakos G, Zachman K $\&$ Chrousos GP (1997). Blood pressure in children and adolescents with Cushing's syndrome before and after surgical cure. J ournal of Clinical Endocrinology and Metabolism, 82: 1734-1738.

11. Bingham Ch, Arbogast B, Guillaume GC, Lee J K \& Halberg $F$ (1982). Inferential statistical methods for estimating and comparing cosinor parameters. Chronobiologia, 9: 397-439.

12. Kubacek $L$, Valach $A \&$ \&ikulecky $M$ (1997). Time series analysis with periodic 
components. Computer Program Manual. ComTel, Bratislava.

13. Diem K \& Seldrup J (1982). Geigy Scientific Tables. Vol. 2. Introduction to Statistics. Statistical Tables. Mathematical Formulae. CIBA-GEIGY, Basel.

14. Campbell MJ \& Gardner MJ (1988). Calculating confidence intervals for some non-parametric analyses. British Medical
J ournal, 296: 1454-1456.

15. Danese RD \& Aron DC (1994). Cushing's syndrome and hypertension. Endocrinology and Metabolism Clinics of North America, 23: 299-324.

16. Fallo F, Sonino N, Barzon L, Pistorello $M$, Pagotto U, Paoletta A \& Boscaro M (1996). Effect of surgical treatment on hypertension in Cushing syndrome. American J our- nal of Hypertension, 9: 77-80.

17. Welbourn RB (1985). Survival and causes of death after adrenalectomy for Cushing's disease. Surgery, 97: 16-20.

18. Ross EJ \& Linch DC (1985). The clinical response to treatment in adult Cushing's syndrome following remission of hypercortisolemia. Postgraduate Medical J ournal, 61: 205-211. 